Supporting information

\title{
CRYSTAL STRUCTURES OF THE CARBOXYL TERMINAL DOMAIN OF \\ RAT 10-FORMYLTETRAHYDROFOLATE DEHYDROGENASE: \\ IMPLICATIONS FOR THE CATALYTIC MECHANISM OF ALDEHYDE \\ DEHYDROGENASES
}

Yaroslav Tsybovsky, Henry Donato, Natalia I. Krupenko, Christopher Davies, and Sergey A. Krupenko

From the Department of Biochemistry and Molecular Biology, Medical University of South Carolina, Charleston, South Carolina, 29425

Address correspondence to:

Sergey A. Krupenko, Department of Biochemistry and Molecular Biology, Medical University of South Carolina, 173 Ashley Ave., Charleston, South Carolina, 29425, Tel. 843 792-0845; Fax 843 792-8565; E-Mail: krupenko@musc.edu

Christopher Davies, Department of Biochemistry and Molecular Biology, Medical University of South Carolina, 173 Ashley Ave., Charleston, South Carolina, 29425, Tel. 843 792-1468; Fax 843 792-8568; E-mail: davies@,musc.edu 
1. Conformations of NADP in binary complexes with $C_{t}-F D H$.
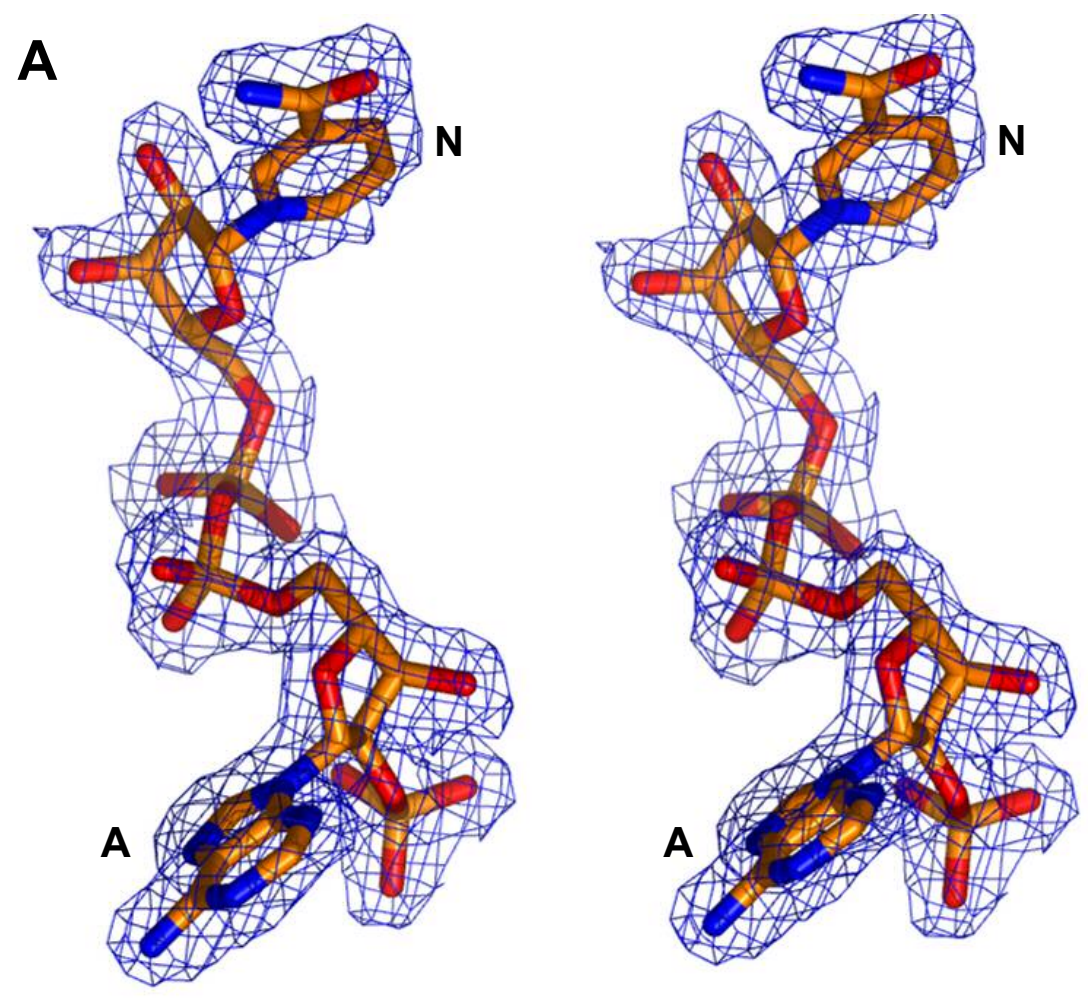

B
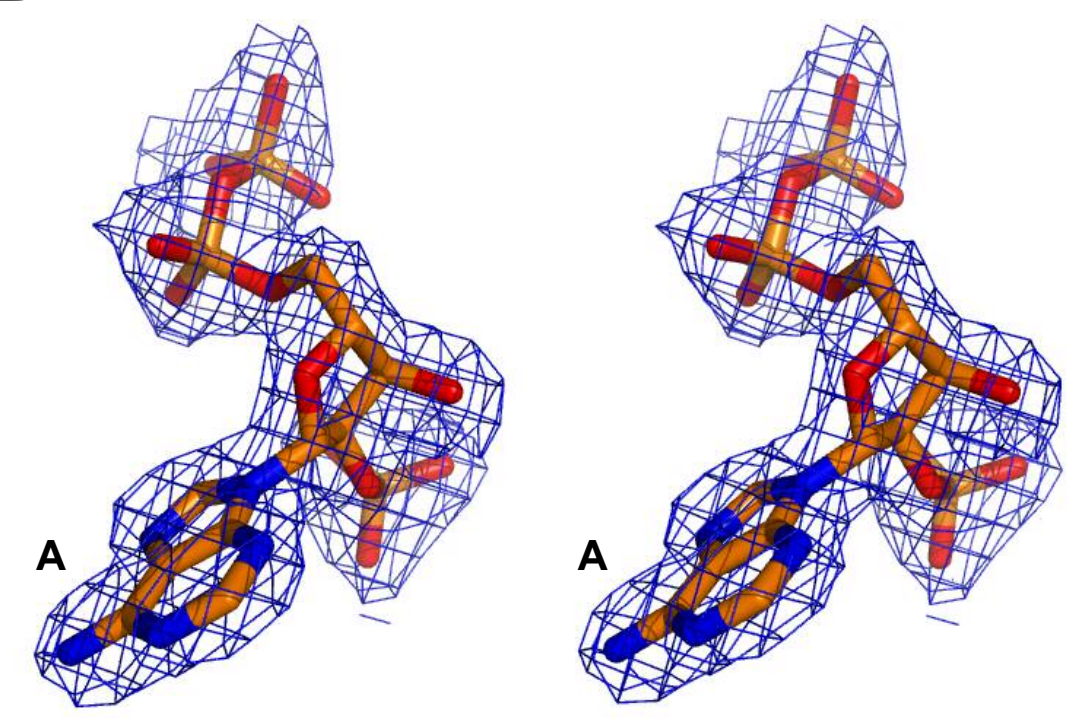

Fig. S1: Electron density corresponding to the coenzyme in binary complexes with $\mathrm{C}_{\mathrm{t}^{-}}$ FDH. $A$, Stereo views of $\mathrm{NADP}^{+}$and $B$, NADPH. In both cases, $2\left|F_{O}\right|-\left|F_{C}\right|$ electron density maps are contoured at $1 \sigma$ are shown in blue, set against the final, refined model. 
Nicotinamide and adenine nucleotides are labeled $\mathrm{N}$ and $\mathrm{A}$, respectively. The figure was prepared using PyMOL (www.pymol.sourceforge.net).

2. Possible chemical modification of the active site cysteine in native structures of $A L D H s$. The electron density in the active site of the apoenzyme structure of $\mathrm{C}_{\mathrm{t}}-\mathrm{FDH}$ indicates a possible covalent modification of Cys707. Keeping in mind the high structural similarity of the active site among the ALDH family, we downloaded structure factors and coordinates for a number of ALDH structures available in the Protein Data Bank (l). Examination of electron density maps calculated from these data showed similar modifications of the sulfur atoms, consistent with the cysteine being oxidized, in the following ALDH enzymes: human mitochondrial (PDB codes 1001, 1O02, 1005, 1ZUM) (2, 3), betaine ALDH from cod liver (PDB codes 1A4S) (4), sheep liver (PDB code 1BXS) (5), E. coli (PDB code 1EYY) (6) and Vibrio harveyi (PDB code 1WNB) (7). In some cases, the electron density had previously been interpreted as water molecules.

3. The covalent bond between the active site cysteine and $C 4$ of $N A D P^{+}$. Refinement of this structure (in REFMAC5) without the restraint of a covalent link moved the sulfur atom $2.5 \AA$ away from the $\mathrm{C} 4$ atom, where it was observed within a strong peak of negative density in the $\left|F_{\mathrm{O}}\right|-\left|F_{\mathrm{C}}\right|$ map. At the same time, a positive peak was observed in the position occupied by the sulfur atom prior to refinement. Refinement of the structure with the two atoms positioned as a covalent link but with their occupancies set to zero, caused a single oval-shaped positive electron density peak in the $\left|F_{\mathrm{O}}\right|-\left|F_{\mathrm{C}}\right|$ map 
surrounding the two atoms that could be seen at a contour of up to $6 \sigma$ (see Fig. 7 in main text, blue contour). Refinement with all the atoms of Cys707 and $\mathrm{NADP}^{+}$set to zero resulted in continuous positive density that encompassed all atoms of Cys707 and $\mathrm{NADP}^{+}$(see Fig. 7 in main text, green contour). Using a link statement, we defined a covalent link between the Cys707 sulfur atom and the $\mathrm{C} 4$ atom of the nicotinamide ring of the cofactor and performed a series of refinements in which the length of the covalent link was varied. These showed that $1.6 \AA$ was the optimal distance between the two atoms, consistent with a covalent bond between these two atoms. After refinement, the Bfactor of the sulfur atom that formed the covalent link $\left(24.1 \AA^{2}\right)$ was intermediate between the average B-factor of the protein side chains atoms $\left(21.0 \AA^{2}\right)$ and the atoms of the nicotinamide ring $\left(27.7 \AA^{2}\right)$.

4. Possible covalent link between the active site cysteine and $\mathrm{C4}$ of $\mathrm{NADP}^{+}$in the structure of the allosteric non-phosphorylating GAPDH from Thermoproteus tenax. Examination of other ALDH structures in the PDB where the coenzyme was bound in the extended conformation revealed a likely covalent bond between $\mathrm{NADP}^{+}$and Cys297 in the structure of the allosteric non-phosphorylating GAPDH from Thermoproteus tenax (PDB code $1 \mathrm{KY} 8$ ) (8). In $2\left|F_{\mathrm{O}}\right|-\left|F_{\mathrm{C}}\right|$ electron density maps calculated from diffraction data and coordinates deposited in the PDB, we observed the $\mathrm{C} 4$ atom of $\mathrm{NADP}^{+}$to be outside the electron density (contoured at $1 \sigma$ level) whereas the $\left|F_{\mathrm{O}}\right|-\left|F_{\mathrm{C}}\right|$ map (at $2.5 \sigma$ ) showed a small positive peak between the $\mathrm{C}_{\beta}$ atom of Cys297 and the $\mathrm{C} 4$ atom (Fig. S2A). Introducing a second conformation for Cys297 that was covalently linked to the C4 atom of the nicotinamide led to a refined structure in which the $\mathrm{C} 4$ atom was positioned 
within the $2\left|F_{\mathrm{O}}\right|-\left|F_{\mathrm{C}}\right|$ density $1.7 \AA$ away from the sulfur atom and no positive $\left|F_{O}\right|-\left|F_{C}\right|$ density could be seen at $2.5 \sigma$. (Fig. S2B). Moreover, B factors of the sulfur atoms of Cys297 and the $\mathrm{C} 4$ atom of $\mathrm{NADP}^{+}$, as well as those of the entire nicotinamide ring, were significantly reduced after this refinement.

\section{A}
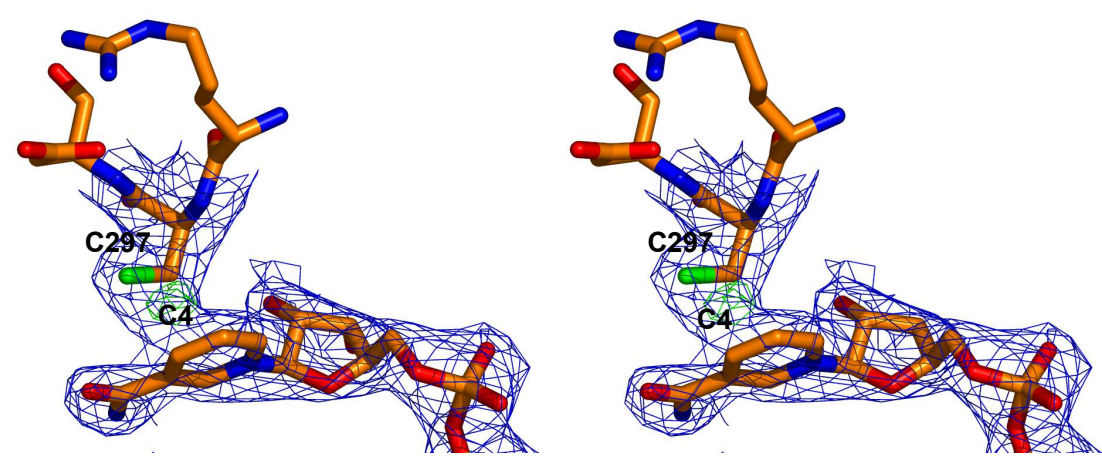

B
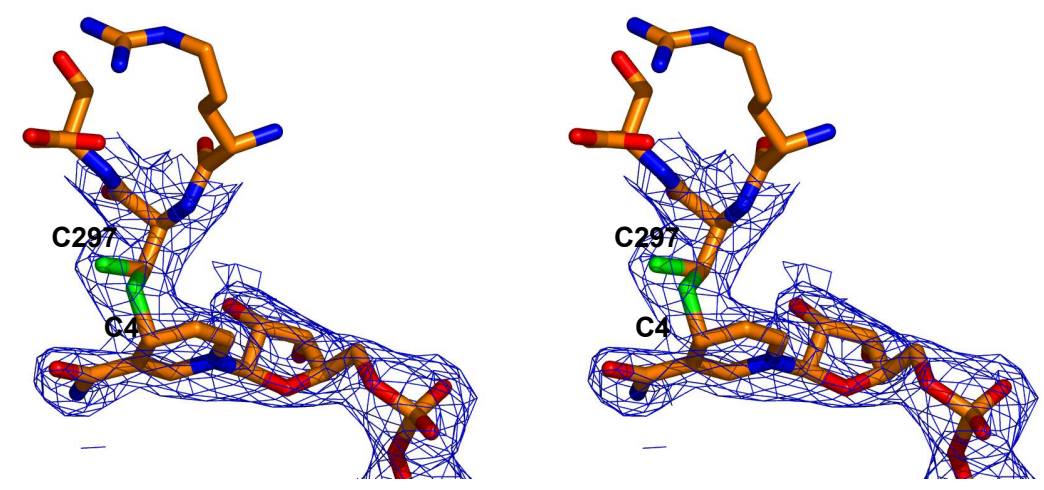

Fig. S2: Potential covalent link in the structure of allosteric non-phosphorylating glyceraldehyde-3-phosphate dehydrogenase from Thermoproteus tenax. A, The structure as retrieved from the Protein Data Bank. Note the positive difference electron density between the sulphur of Cys297 and $\mathrm{C} 4$ of nicotinamide. $B$, The structure after refinement with a second conformation of the Cys 297 covalently linked to C4 of $\mathrm{NADP}^{+}$. Note the disappearance of the $\left|F_{\mathrm{O}}\right|-\left|F_{\mathrm{C}}\right|$ difference density after refinement in which a covalent link between sulfur and $\mathrm{C} 4$ was defined. For both panels, the $2\left|F_{\mathrm{O}}\right|-\left|F_{\mathrm{C}}\right|$ density map is colored 
blue and contoured at $0.85 \sigma$ level, and the positive $\left|F_{\mathrm{O}}\right|-\left|F_{\mathrm{C}}\right|$ density map is colored green and contoured at 2.5 o. The figure was prepared using PyMOL (www.pymol.sourceforge.net).

5. Spectroscopic evidence of the presence of a covalent bond between the sulfur atom of Cys 707 and the C4 atom of $N A D P^{+}$in $C_{t}-F D H$. The absorption spectra of $\mathrm{C}_{\mathrm{t}}-\mathrm{FDH}$ in the presence of $\mathrm{NADP}^{+}$are clearly different from those obtained in the absence of the coenzyme (Fig. S3A). These differences are more pronounced in the regions $260-290 \mathrm{~nm}$ and 300-340 $\mathrm{nm}$ and are likely to originate from one of the following: (i) changes in the absorption spectrum of the protein in the presence of $\mathrm{NADP}^{+}$, (ii) light absorption by the covalent adduct, and (iii) light absorption by $\mathrm{NADP}^{+}$itself. To examine these possibilities, we generated a mutant protein having a serine in place of the active site cysteine $\left(\mathrm{C}_{\mathrm{t}}-\mathrm{FDH}-\mathrm{C} 707 \mathrm{~S}\right)$. The crystal structure of the binary complex of $\mathrm{C}_{\mathrm{t}}-\mathrm{FDH}-\mathrm{C} 707 \mathrm{~S}$ with $\mathrm{NADP}^{+}$solved to $2.3 \AA$ shows no presence of the covalent bond, although the conformation of the coenzyme remains identical to that of in the $\mathrm{NADP}^{+}-\mathrm{C}_{\mathrm{t}}-\mathrm{FDH}$ complex, with the exception of a slight shift in the position of the nicotinamide ring that brings the $\mathrm{C} 4$ atom $3.3 \AA$ away from the side chain oxygen of Ser707 (data not shown). Addition of $\mathrm{NADP}^{+}$to $\mathrm{C}_{\mathrm{t}}-\mathrm{FDH}-\mathrm{C} 707 \mathrm{~S}$ induces an identical increase in absorbance in the 260-290 nm region of the spectrum (Fig. S3B). In contrast, the spectrum in the region 300-340 $\mathrm{nm}$ coincides with the one recorded in the absence of $\mathrm{NADP}^{+}$(Fig. S3B). $\mathrm{NADP}^{+}$itself does not have an absorption peak in this region (Fig. S3A and B). Therefore, the small but reliably detected peak at around $320 \mathrm{~nm}$ in the absorption spectrum obtained by subtracting the spectrum of $\mathrm{C}_{\mathrm{t}}-\mathrm{FDH}$ from the spectrum of $\mathrm{C}_{\mathrm{t}}-\mathrm{FDH}$ 
in the presence of $\mathrm{NADP}^{+}$(Fig. S3C) should be attributed to the covalent adduct. In support of this conclusion, increasing the concentration of $\mathrm{NADP}^{+}$significantly over the concentration of the coenzyme binding sites of $\mathrm{C}_{\mathrm{t}}$-FDH shows no detectable effect on the height of this peak (data not shown). Absorption in this spectral region is typical of adducts observed between $\mathrm{NAD}(\mathrm{P})$ and sulfhydryl compounds $((9)$, see also Discussion in (10)).
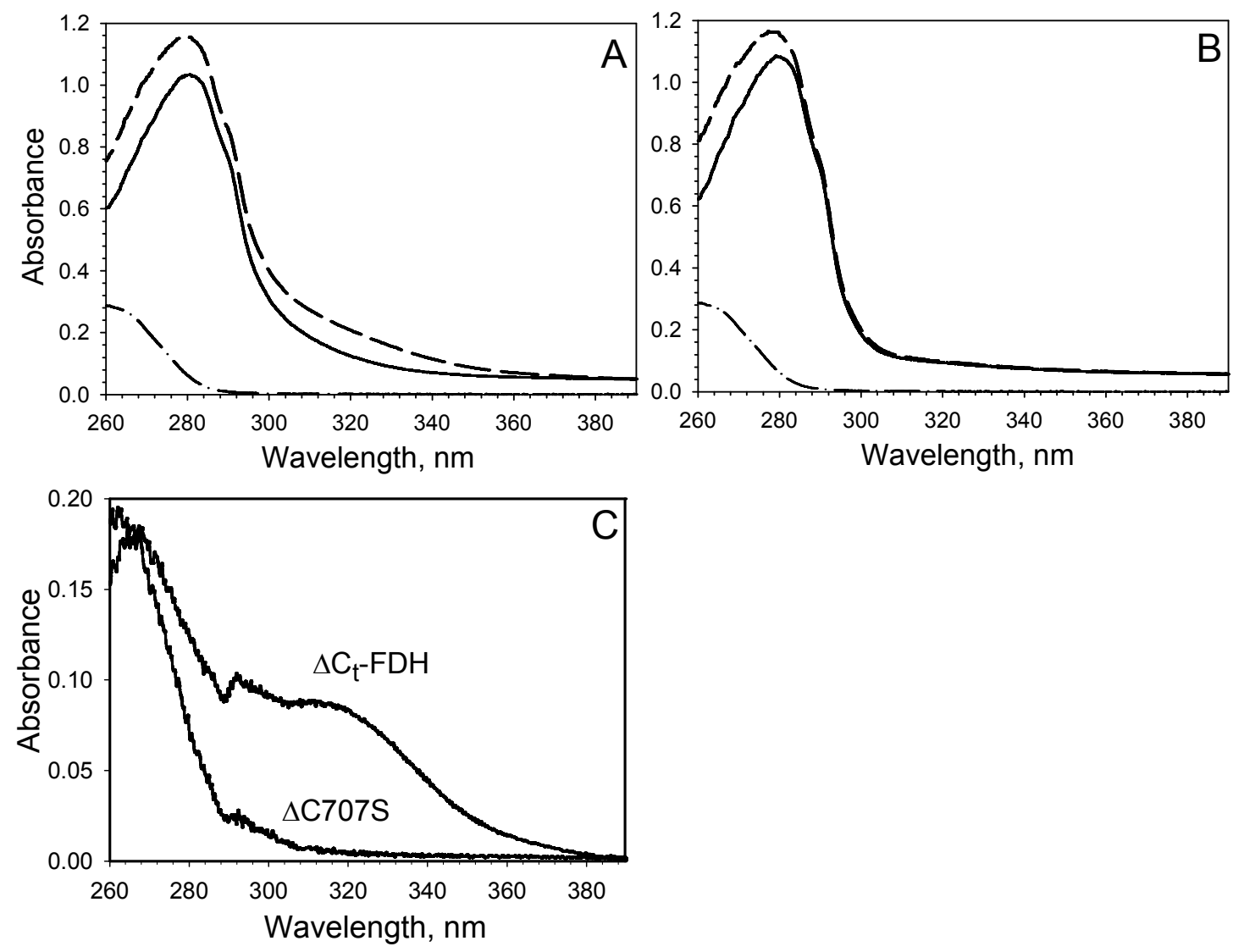

Fig. S3: Absorption spectra of $A, \mathrm{C}_{\mathrm{t}}-\mathrm{FDH}$ and $B$, the $\mathrm{C}_{\mathrm{t}}-\mathrm{FDH}-\mathrm{C} 707 \mathrm{~S}$ mutant in the absence of $\mathrm{NADP}^{+}$(solid lines) and in the presence of the coenzyme (dashed lines). The protein subunit and $\mathrm{NADP}^{+}$concentrations are $26 \mu \mathrm{M}$. The dash-and-dot lines represent the absorption spectrum of $\mathrm{NADP}^{+}$in the absence of the protein. $C$, the curves obtained 
by subtracting the spectra of $\mathrm{C}_{\mathrm{t}}-\mathrm{FDH}$ and $\mathrm{C}_{\mathrm{t}}-\mathrm{FDH}-\mathrm{C} 707 \mathrm{~S}$ in the absence of the coenzyme from those recorded in the presence of $\mathrm{NADP}^{+}$(denoted as $\Delta \mathrm{C}_{\mathrm{t}} \mathrm{FDH}$ and $\Delta \mathrm{C} 707 \mathrm{~S}$, respectively). 


\section{REFERENCES}

1. Bernstein, F. C., Koetzle, T. F., Williams, G. J., Meyer, E. F., Jr., Brice, M. D., Rodgers, J. R., Kennard, O., Shimanouchi, T., and Tasumi, M. (1977) The Protein Data Bank: a computer-based archival file for macromolecular structures, J. Mol. Biol. 112, 535-542.

2. Perez-Miller, S. J., and Hurley, T. D. (2003) Coenzyme isomerization is integral to catalysis in aldehyde dehydrogenase, Biochemistry 42, 7100-7109.

3. Larson, H. N., Weiner, H., and Hurley, T. D. (2005) Disruption of the coenzyme binding site and dimmer interface revealed in the crystal structure of mitochondrial aldehyde dehydrogenase "Asian" variant, J. Biol. Chem. 280, 30550-30556.

4. Johansson, K., El-Ahmad, M., Ramaswamy, S., Hjelmqvist, L., Jornvall, H., and Eklund, H. (1998) Structure of betaine aldehyde dehydrogenase at $2.1 \mathrm{~A}$ resolution, Protein Sci. 7, 2106-2117.

5. Moore, S. A., Baker, H. M., Blythe, T. J., Kitson, K. E., Kitson, T. M., and Baker, E. N. (1998) Sheep liver cytosolic aldehyde dehydrogenase: the structure reveals the basis for the retinal specificity of class 1 aldehyde dehydrogenases, Structure $6,1541-1551$.

6. Gruez, A., Roig-Zamboni, V., Grisel, S., Salomoni, A., Valencia, C., Campanacci, V., Tegoni, M., and Cambillau, C. (2004) Crystal structure and kinetics identify Escherichia coli YdcW gene product as a medium-chain aldehyde dehydrogenase, J. Mol. Biol. 343, 29-41. 
7. Ahvazi, B., Coulombe, R., Delarge, M., Vedadi, M., Zhang, L., Meighen, E., and Vrielink, A. (2000) Crystal structure of the NADP+-dependent aldehyde dehydrogenase from Vibrio harveyi: structural implications for cofactor specificity and affinity, Biochem. J. 349 Pt 3, 853-861.

8. Pohl, E., Brunner, N., Wilmanns, M., and Hensel, R. (2002) The crystal structure of the allosteric non-phosphorylating glyceraldehyde-3-phosphate dehydrogenase from the hyperthermophilic archaeum Thermoproteus tenax, J. Biol. Chem. 277, 19938-19945.

9. van Eyes, J., and Kaplan, N.O. (1957) The addition of sulfhydryl compounds to diphosphopyridine nucleotide and its analogues, J. Biol. Chem. 228, 305-314.

10. Hackett, C.S., Novoa, W.B., Ozols, J., and Strittmatter, P. (1986) Identification of the essential cysteine residue of NADH-cytochrome b5 reductase, J. Biol. Chem. $261,9854-9857$. 